\title{
Circadian asthma airway responses are gated by REV-ERB
}

DOI:

10.1183/13993003.02407-2019

\section{Document Version}

Accepted author manuscript

Link to publication record in Manchester Research Explorer

\section{Citation for published version (APA):}

Durrington, H. J., Krakowiak, K., Meijer, P., Begley, N., Maidstone, R., Goosey, L., Gibbs, J. E., Blaikley, J. F., Gregory, L. G., Lloyd, C. M., Loudon, A. S. I., \& Ray, D. W. (2020). Circadian asthma airway responses are gated by REV-ERB. European Respiratory Journal, 56, [1902407]. https://doi.org/10.1183/13993003.02407-2019

\section{Published in:}

European Respiratory Journal

\section{Citing this paper}

Please note that where the full-text provided on Manchester Research Explorer is the Author Accepted Manuscript or Proof version this may differ from the final Published version. If citing, it is advised that you check and use the publisher's definitive version.

\section{General rights}

Copyright and moral rights for the publications made accessible in the Research Explorer are retained by the authors and/or other copyright owners and it is a condition of accessing publications that users recognise and abide by the legal requirements associated with these rights.

\section{Takedown policy}

If you believe that this document breaches copyright please refer to the University of Manchester's Takedown Procedures [http://man.ac.uk/04Y6Bo] or contact uml.scholarlycommunications@manchester.ac.uk providing relevant details, so we can investigate your claim.

\section{OPEN ACCESS}




\title{
Circadian asthma airway responses are gated by REV-ERBa
}

\author{
Hannah J. Durrington (101,2, Karolina Krakowiak ${ }^{1}$, Peter Meijer ${ }^{3}$, Nicola Begley ${ }^{3}$, \\ Robert Maidstone ${ }^{4}$, Laurence Goosey ${ }^{3}$, Julie E. Gibbs ${ }^{3}$, John F. Blaikley ${ }^{1,2}$, \\ Lisa G. Gregory ${ }^{5}$, Clare M. Lloyd $\mathbb{1}^{5}$, Andrew S.I. Loudon ${ }^{3}$ and David W. Ray $\mathbb{1}^{3,6,7}$
}

Affiliations: ${ }^{1}$ Division of Infection, Immunity and Respiratory Medicine, School of Biological Sciences, Faculty of Biology, Medicine and Health, University of Manchester, Manchester, UK. ${ }^{2}$ Wythenshawe Hospital, University Hospital of South Manchester, Manchester University NHS Foundation Trust (MFT), Manchester, UK. ${ }^{3}$ Division of Diabetes, Endocrinology and Gastroenterology, School of Medical Sciences, Faculty of Biology, Medicine and Health, University of Manchester, Manchester, UK. ${ }^{4}$ Division of Informatics, Imaging and Data Sciences, School of Biological Sciences, Faculty of Biology, Medicine and Health, University of Manchester, Manchester, UK. ${ }^{5}$ National Heart and Lung Institute, Imperial College, London, UK. ${ }^{6}$ NIHR Oxford Biomedical Research Centre, John Radcliffe Hospital, Oxford, UK. ${ }^{7}$ Oxford Centre for Diabetes, Endocrinology and Metabolism, University of Oxford, Oxford, UK

Correspondence: Hannah J. Durrington, Room 3.012, AV Hill Building, Upper Brook Street, University of Manchester, Manchester M13 9PT, UK. E-mail: Hannah.durringtonamanchester.ac.uk

@ERSpublications

REV-ERB $\alpha$ gates airway hyper-responsiveness by time of day. Future asthma therapies should aim to dose anti-muscarinic agents at the most efficacious time of day (chronotherapy) and modulate the molecular clock https://bit.ly/37qY4sC

Cite this article as: Durrington HJ, Krakowiak K, Meijer $\mathrm{P}$, et al. Circadian asthma airway responses are gated by REV-ERB $\alpha$. Eur Respir J 2020; 56: 1902407 [https://doi.org/10.1183/13993003.02407-2019].

\section{ABSTRACT}

Background: The circadian clock powerfully regulates inflammation and the clock protein REV-ERB $\alpha$ is known to play a key role as a repressor of the inflammatory response. Asthma is an inflammatory disease of the airways with a strong time of day rhythm. Airway hyper-responsiveness (AHR) is a dominant feature of asthma; however, it is not known if this is under clock control.

Objectives: To determine if allergy-mediated AHR is gated by the clock protein REV-ERB $\alpha$.

Methods: After exposure to the intra-nasal house dust mite (HDM) allergen challenge model at either dawn or dusk, AHR to methacholine was measured invasively in mice.

Main results: Wild-type (WT) mice show markedly different time of day AHR responses (maximal at dusk/start of the active phase), both in vivo and ex vivo, in precision cut lung slices. Time of day effects on AHR were abolished in mice lacking the clock gene Rev-erb $\alpha$, indicating that such effects on asthma response are likely to be mediated via the circadian clock. We suggest that muscarinic receptors one (Chrm 1) and three (Chrm 3) may play a role in this pathway.

Conclusions: We identify a novel circuit regulating a core process in asthma, potentially involving circadian control of muscarinic receptor expression, in a REV-ERB $\alpha$ dependent fashion.

Clinical implication: These insights suggest the importance of considering the timing of drug administration in clinic trials and in clinical practice (chronotherapy). 


\section{Introduction}

Asthma is a chronic inflammatory disease of the airways and displays a strong relationship to circadian rhythm [1-4]. Asthma-associated mortality is strongly time of day dependent, peaking overnight between midnight and 08:00 [5]. Airway hyper-responsiveness (AHR), a cardinal feature of asthma [6, 7], involves increased sensitivity of the airways to bronchoconstrictor challenge, such as by methacholine. As such, AHR is clinically useful in diagnosing asthma; however, there is a diurnal variation in AHR in asthma, with a peak at around 04:00, the time of maximal disease expression [8-13]. Potential causes for this diurnal change in AHR in asthma remain undefined, but may be important for improved asthma treatment.

Circadian rhythms are generated by a molecular clock that is expressed in virtually all cells. A central clock in the suprachiasmatic nucleus of the brain synchronises peripheral tissue clocks via neural and humoral mediators. The cellular circadian molecular clock consists of a positive arm (CLOCK and BMAL1 heterodimers), driving transcription of two inhibitory arms (PER/CRY and REV-ERB $\alpha / R E V-E R B \beta$ ), which feedback to inhibit BMAL1/CLOCK heterodimer transactivation function [14]. The circadian clock powerfully regulates inflammation [15-17] and $\mathrm{REV}-\mathrm{ERB} \alpha$ plays a key role as a repressor of the inflammatory response [18].

Here we explore the biology of REV-ERB $\alpha$ and address whether this protein acts as a circadian mediator, gating AHR following allergic challenge. Using the house dust mite (HDM) [19] mouse model for allergic airways disease [20], as well as an in-vitro lung slice model, we investigated the role of airway smooth muscle in the circadian gating of AHR. We found that time of day effects in AHR following allergen challenge were ablated in REV-ERB $\alpha$-deficient mice, as was rhythmic expression of key muscarinic receptor subclasses, mediating cholinergic smooth-muscle responses. Thus, we have identified a pathway linking the core cellular clock, through REV-ERB $\alpha$, to airway reactivity, smooth-muscle tone and airway narrowing.

\section{Methods}

Animals

All experimental procedures were carried out in accordance with the Animals (Scientific Procedures) Act, 1986. Rev-erbo $\alpha^{-1-}$ mice were provided by Ueli Schibler (University of Geneva, Geneva, Switzerland) [21]. Wild-type (WT) C57Bl/6 J control mice and Rev-erb ${ }^{-1-}$ mice were individually housed in $12 \mathrm{~h}: 12 \mathrm{~h}$ light: dark cycles. Zeitgeber time zero (ZT0) is when lights are turned on in the animal house and ZT12 is when lights are switched off. Female $\mathrm{C} 57 \mathrm{Bl} / 6 \mathrm{~J}$ mice aged 8-12 weeks were used in all experiments.

\section{House dust mite asthma protocol}

Mice were exposed intranasally to $25 \mu \mathrm{g}$ of HDM protein (Citeq Biologics, Groningen, The Netherlands; batch no. 15J02) in $25 \mu \mathrm{L}$ of phosphate-buffered saline (PBS) under anaesthesia 5 days.week ${ }^{-1}$ for 3 weeks [20]. Control mice received intranasal PBS. One group of mice received HDM/PBS at ZT11 (just before lights off/start of the active phase), while a second group received HDM/PBS at ZT23 (just before lights on/start of the rest phase).

\section{Measurement of airway hyper-responsiveness}

Airway resistance was measured $24 \mathrm{~h}$ after final HDM exposure, in response to increasing concentrations (3-100 $\mathrm{mg} \cdot \mathrm{mL}^{-1}$ ) of methacholine (Sigma-Aldrich, Gillingham, UK), using a FlexiVent small animal ventilator (SciReq, Montreal, Canada) [22] as previously described [23].

\section{Collection of serum}

Blood samples in BD Microtainers (Becton, Dickinson and Company, Franklin Lakes, NJ, USA) were placed on ice for $1 \mathrm{~h}$ and then centrifuged ( $5 \mathrm{~min}, 7000 \mathrm{rpm}$ ) to derive serum.

\section{Bronchoalveolar lavage and lung digest}

Bronchoalveolar lavage (BAL) was performed immediately after measurement of AHR [24]. The right inferior and post-caval lobes were taken for lung digest. Lung cells were analysed by flow cytometry [23].

\section{Histology}

Following BAL, the left lung was taken for histology. For haemoatoxylin $(\mathrm{H})$ and eosin $(\mathrm{E})$ stained slides a semi-quantitative scoring system graded the size of lung infiltrates [25]. Goblet cells were counted on periodic acid-Schiff (PAS) stained lung sections using an arbitrary scoring system [26]. 
RNA extraction and real-time quantitative polymerase chain reaction RNA was extracted from the right middle lobe (ReliaPrep RNA Miniprep System, Promega, Madison, WI, USA, catalogue ref. Z6011) and reverse-transcribed (GoScript Reverse Transcription System, Promega, catalogue ref. A5001) before quantitative PCR analysis (KAPA SYBR FAST qPCR Master Mix (2X) Universal Kit, KAPA Biosystems, Wilmington, MA, USA, catalogue ref. KK4601). Relative gene expression was determined via normalization to Gapdh. Primers used were: Qiagen Adrb1 (QT00258692), Adrb2 (QT00253967), Chrm 1 (QT00282527), Chrm 2 (QT00290297), Chrm 3 and Gapdh (QT01658692). Primer sequences were: Nr1d1 (F GTCTCTCCGTTGGCATGTCT, R CCAAGTTCATGGCGCTCT) and Bmal1 (F CCAAGAAAGTATGGACACAGACAAA, R GCATTCTTGATCCTTCCTTGGT).

\section{Enzyme-linked immunosorbent assay (ELISA)}

Serum was analysed for anti-HDM IgE using an IgE mouse ELISA kit (Thermo Fisher Scientific, Waltham, MA, USA, catalogue ref. EMIGHE) or a mouse serum anti-HDM IgE antibody ELISA kit (Chrondrex Inc, Woodinville, WA, USA, catalogue ref. 3037) as per the manufacturer's instructions.

\section{Bioplex}

Bronchoalveolar lavage fluid (BALF) was analysed using a Bio-Plex Pro Mouse Chemokine Panel 33-Plex (Bio-Rad, Watford, UK, catalogue ref. 12002231), on a Bio-Plex 200 system (Bio-Rad).

\section{Lung slice model}

Precision-cut ectopic lung slices $(175 \mu \mathrm{m})$ were prepared [24]. Slices placed on cell culture inserts (Millicell) were imaged using a long-term time lapse microscope (Eclipse Ti Series Inverted Microscope, Nikon Instruments Europe BV, Amsterdam, The Netherlands). Airways were imaged in response to methacholine $(0-100 \mu \mathrm{M})$. Airway size was quantified using ImageJ software (version 1.41o). Airway contraction was measured as a percentage decrease from baseline.

\section{Statistical analysis}

Linear mixed effects modelling was used to determine how AHR changes with increasing dose of nebulised methacholine. Other data was analysed by one-way ANOVA, followed by Tukey's multiple comparison test and was represented as median \pm interquartile range (IQR). IgE data and change in AHR after $75 \mathrm{mg} \cdot \mathrm{mL}^{-1}$ of methacholine were analysed by Mann-Whitney U-tests. Serum IgE, AHR and PCR data is represented as mean \pm standard error of the mean (SEM). For the precision-cut lung slice model, methacholine doseresponse curves were fitted to a three-parameter sigmoidal dose-response curve. An extra sum-of-squares F-test was used to test whether one curve could adequately fit the data for ZT11 and ZT23.

\section{Results}

Airway hyper-responsiveness varies by time of day that house dust mite allergen challenge occurs

The time of day at which WT mice are challenged with HDM significantly impacts the resultant AHR (figure 1a). WT mice were challenged with HDM at either ZT11 (just before lights off and at the start of the active phase for mice) or at ZT23 (just before lights on and at the start of the rest phase in mice). WT mice challenged with HDM at ZT11, in which maximal airway resistance was recorded $24 \mathrm{~h}$ later at ZT11, showed a significant increase in the slope of the methacholine dose-response curve compared to mice challenged at ZT23 (figure 1a) $(\mathrm{p}=0.005)$. This indicates a significant time of challenge effect and suggests increased sensitivity of the airways to the effects of methacholine after HDM challenge at ZT11 compared to ZT23. This was also the case when airway resistance was measured as area under the curve (supplementary figure S1a) $(\mathrm{p}=0.005)$.

WT mice challenged with HDM exhibited increased airway resistance after $75 \mathrm{mg} \cdot \mathrm{mL}^{-1}$ of methacholine at both ZT11 and ZT23 compared to control mice treated with PBS ( $\mathrm{p}=0.007$ for ZT11 and $\mathrm{p}=0.055$ for ZT23). Maximal airway resistance was significantly higher after $75 \mathrm{mg} \cdot \mathrm{mL}^{-1}$ of methacholine in WT mice challenged with HDM at ZT11 compared to challenge at ZT23 (figure 1a) (p=0.05). This was also the case for mean resistance $\left(R_{\mathrm{rs}}\right)$ (figure $\left.1 \mathrm{~b}\right)(\mathrm{p}=0.03)$. There were no differences in lung compliance between groups (figure 1c).

\section{Airway and lung inflammation reveal no time of challenge differences}

Next, we examined BAL to determine whether time of day differences in AHR were associated with airway inflammatory changes. There was a significant increase in total cells from BAL for mice treated with HDM at ZT11, as compared to controls, but not at ZT23. There was no difference by time of challenge (table 1). BAL eosinophils significantly increased following HDM challenge at both ZT11 and at ZT23, compared to controls. No time of challenge differences were seen for differential BAL cell types. BAL macrophages were 

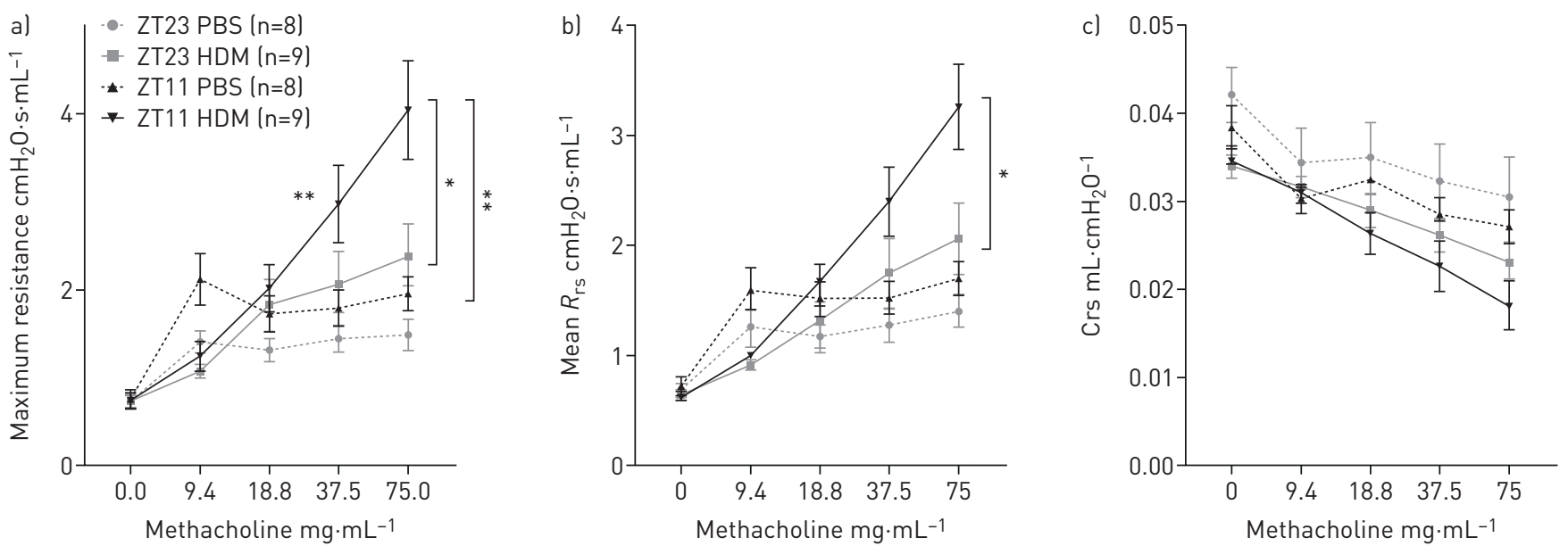

FIGURE 1 House dust mite (HDM) challenge at ZT11, just before the start of the active phase, results in a significant increase in airway hyper-responsiveness (AHR) compared to challenge at ZT23. Panels are as follows: a) AHR to increasing doses of methacholine measured as maximum airway resistance (mean \pm SEM) using FlexiVent in wild-type (WT) mice at ZT11 and ZT23. The slope of the dose-response curve for methacholine is significantly increased after HDM challenge at ZT11 compared to challenge at ZT23 ( $p=0.005$ ) (by mixed linear modelling). WT mice challenged with HDM exhibited increased airway resistance after $75 \mathrm{mg} \cdot \mathrm{mL}^{-1}$ of methacholine at both ZT11 and ZT23 compared to control mice treated with phosphate-buffered saline (PBS) ( $p=0.007$ for ZT11 and $p=0.055$ for ZT23, by Mann-Whitney U-test). Maximal airway resistance was significantly higher after $75 \mathrm{mg} \cdot \mathrm{mL}^{-1}$ of methacholine in WT mice challenged with HDM at ZT11 compared to challenge at ZT23 ( $\mathrm{p}=0.05$, by Mann-Whitney U-test). Baseline airway resistance was higher in control (PBS-treated) mice challenged at ZT11 compared to challenge at ZT23 b) AHR to increasing doses of methacholine was measured as mean resistance $\left(R_{\mathrm{rs}}\right)$ (mean $\left.\pm \mathrm{SEM}\right)$ in WT mice challenged at ZT11 and ZT23. WT mice challenged at ZT11 exhibited significantly increased $R_{\mathrm{rs}}$ after $75 \mathrm{mg} \cdot \mathrm{mL}^{-1}$ of methacholine compared to challenge at ZT23 ( $p=0.03$, by MannWhitney U-test); c) compliance (Crs) to increasing doses of methacholine was measured (mean \pm SEM) using FlexiVent in WT mice challenged at ZT11 and ZT23. There was a reduction in compliance in both HDM-challenged mice and PBS-challenged mice; however, there was no time of day difference (by Mann-Whitney U-test). SEM: standard error of the mean. ${ }^{*}: p \leqslant 0.05 ;{ }^{* *}: p \leqslant 0.01$.

significantly reduced at ZT23 after HDM challenge. HDM-specific IgE significantly increased after HDM challenge in WT mice; however, there was no time of challenge difference, indicating similar sensitisation and acquisition of adaptive immunity (supplementary figure S1b).

Next we analysed inflammatory cells present in lung digests. There was an increase in total immune cell content after HDM challenge, but this only reached significance at ZT23 and there was no time of HDM challenge difference (figure 2a). There was also a significant increase in lung eosinophils after HDM challenge, but again no time of challenge difference (figure $2 b$ ).

TABLE 1 Bronchoalveolar lavage fluid (BALF) differential immune cell counts after house dust mite (HDM) challenge at either ZT11 or ZT23 reveal no time of challenge differences

\begin{tabular}{|c|c|c|c|c|}
\hline BAL cell type & Challenge & ZT11 & ZT23 & Adjusted p-value \\
\hline Eosinophils $\%$ of cell total & HDM & $25.5(19.6-50.8)$ & $46.5(18-50.2)$ & 1.0 \\
\hline Neutrophils $\%$ of cell total & HDM & $25.65(14.53-48.45)$ & $32(15.6-50.8)$ & 1.0 \\
\hline \multirow[t]{2}{*}{ Macrophages $\%$ of cell total } & PBS & $28.6(17.4-46.05)$ & $67(63.35-73.6)$ & 1.0 \\
\hline & HDM & 7.03 (5.45-12.45) & $5.52(1.11-9.59)$ & 1.0 \\
\hline \multirow[t]{2}{*}{ Cell total $\times 10^{5}$ per $\mathrm{mL}$} & PBS & $0.75(0.46-1.32)$ & 1.134 (0.72-2.83) & 0.97 \\
\hline & HDM & $4.36(3.48-15.2)$ & $4.09(2.73-8.12)$ & 0.94 \\
\hline
\end{tabular}

Data are presented as median (interquartile range), unless otherwise stated. BAL cell total was increased after HDM challenge ( $\leqslant \leqslant 0.01$ ) at ZT11 but not at ZT23, as compared to controls. There was no significant difference by time of challenge. BAL eosinophils were significantly increased following HDM challenge at both ZT11 and at ZT23, as compared to PBS challenge ( $p \leqslant 0.05$ and $p \leqslant 0.05$, respectively). No time of challenge differences were seen for differential BAL cell types. There was a significant reduction in BAL macrophages at ZT23 after HDM challenge compared to PBS challenge $(p \leqslant 0.05)$. $p$-Values are determined by one-way ANOVA, followed by the Tukey multiple comparison adjustment (n=9-11 per treatment group). IQR: interquartile range; BAL: bronchoalveolar lavage; PBS: phosphate-buffered saline. 

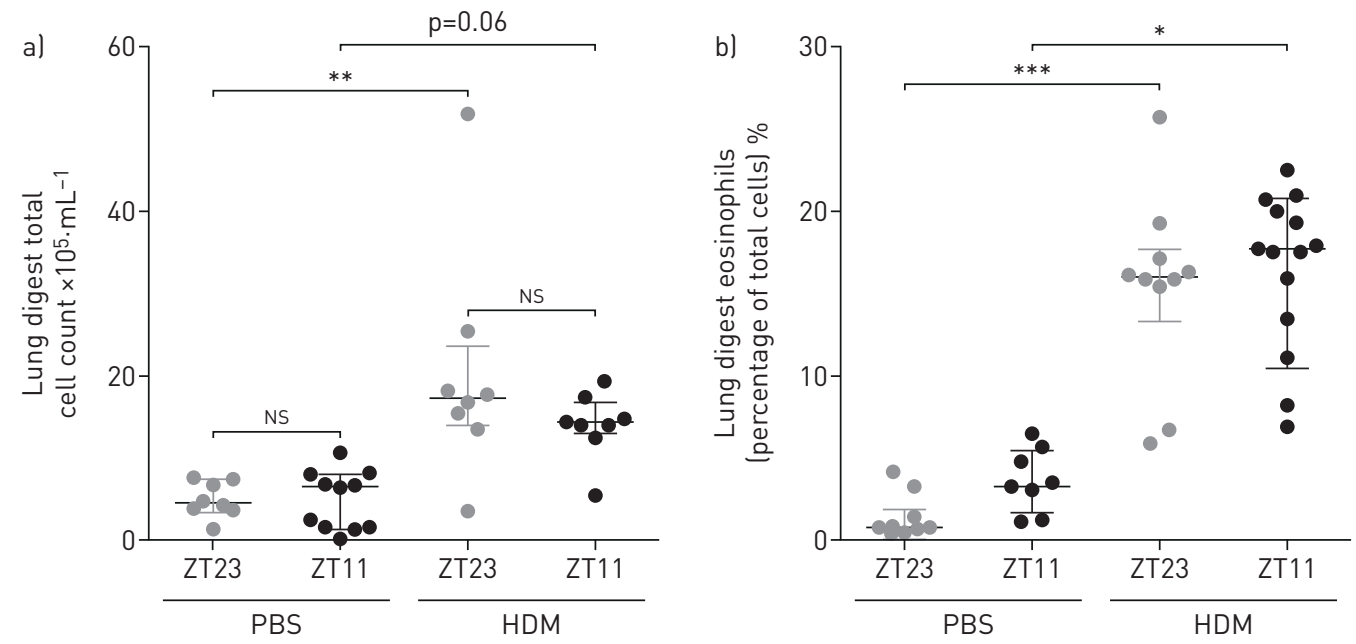

c)

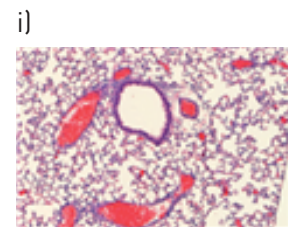

iii)

ZT11

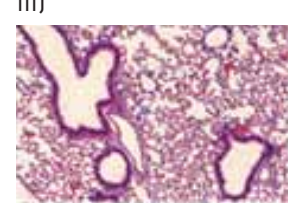

PBS

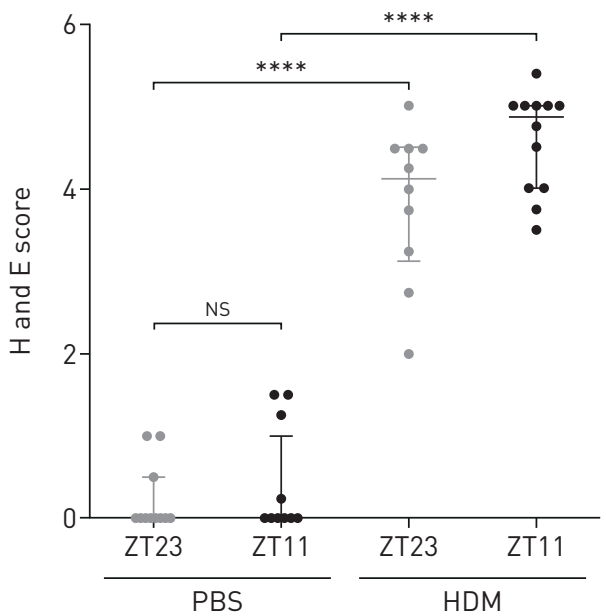

d)

ii)

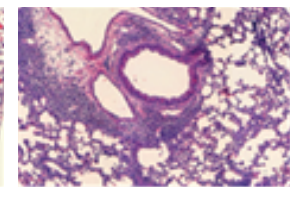

iv)

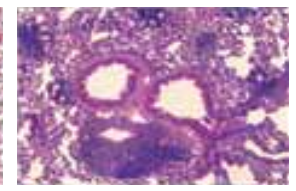

HDM i)

ZT23

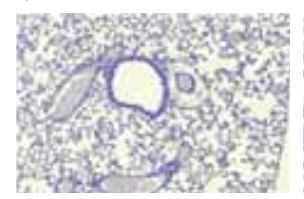

iii)

ZT11

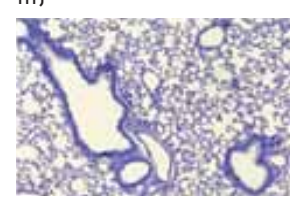

PBS

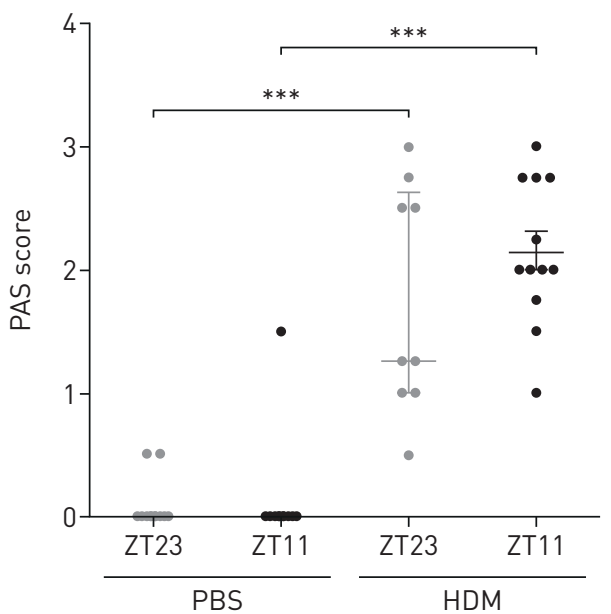

FIGURE 2 Eosinophilic lung inflammation increases after house dust mite (HDM) challenge; however, no real time of challenge difference is observed. Panels are as follows: al total cell count from lung digests in wild-type (WT) mice (median \pm IQR). Total cell count increased after HDM challenge compared to controls using phosphate-buffered saline (PBS) $(p<0.01$ at ZT23 and $p=0.06$ at ZT11). There was no time of challenge difference after PBS or HDM challenge (by one-way ANOVA followed by Tukey's multiple comparison test, $\mathrm{n}=8-11$ per treatment group); b) eosinophils in lung digests from WT mice (median \pm (QR) significantly increased after HDM challenge compared to PBS challenge ( $p<0.001$ at ZT23 and $p<0.05$ at ZT11), although there was no time of challenge difference for either PBS or HDM challenge lone-way ANOVA, followed by Tukey's multiple comparison test, $\mathrm{n}=8-11$ per treatment group); c) HDM challenge at ZT11 and ZT23 caused predominantly eosinophilic inflammation around the bronchioles and blood vessels compared to PBS challenge (haemoatoxylin $(H)$ and eosin (E) staining, subpanels $i-i v, p<0.0001$ at both ZT23 and ZT11). There was no time of challenge difference after either PBS or HDM challenge (data: median \pm IQR; one-way ANOVA, followed by Tukey's multiple comparison test, $n=10-12$ per treatment group); d) periodic acid-Schiff (PAS) staining shows increased mucus presence on the bronchial epithelium in the lungs of WT mice treated with 
HDM at both ZT11 and ZT23, although there was no PAS staining to be seen in PBS-treated mice (subpanels i-iv). However, HDM-challenged mice did have significantly increased PAS scores compared to controls $(p<0.001$ at both ZT23 and ZT11), but no time of challenge differences were observed (data: median \pm IQR, one-way ANOVA, followed by Tukey's multiple comparison test, $n=10-12$ per treatment group). NS: nonsignificant; IQR: interquartile range. ${ }^{*}: p<0.05 ;{ }^{* *}: p<0.01 ;{ }^{* * *}: p<0.001 ;{ }^{* * *}: p<0.0001$.

Histology revealed a significant increase in eosinophil infiltration around the bronchioles and blood vessels within the lung following HDM challenge, as compared to control mice. However, there was no time of challenge difference (figure 2c). There was increased mucus in PAS stained lung sections after HDM challenge compared to controls, but no time of challenge difference in PAS scores (figure $2 \mathrm{~d}$ ).

\section{REV-ERB $\alpha$ is a negative repressor of airway hyper-responsiveness}

The functions of two components of the molecular clock within the lungs of WT mice were investigated. We focussed on BMAL1, the only non-redundant clock component and the major element of the positive arm of the clock. BMAL1 has been implicated in the circadian control of inflammation [27-30]. We also studied REV-ERB $\alpha$, a component of the negative arm of the clock and a known regulator of inflammation $[16,18]$, itself repressed by inflammation. Bmal1 expression is in antiphase to Rev-erb $\alpha$ expression in PBS-treated mice (figures $3 \mathrm{a}$ and $3 \mathrm{~b}$ ). There was a significant time of day difference in Rev-erb $\alpha$ expression at baseline, with high levels of Rev-erb $\alpha$ expression at ZT11, close to the predicted circadian peak of expression and low levels of expression at ZT23 (figure 3a). After HDM challenge there is reduced expression of both Rev-erb $\alpha$ and Bmal1, with a loss of time of day of expression within the lung (figures $3 \mathrm{a}$ and $3 \mathrm{~b})$.

The change in Rev-erb $\alpha$ expression seen after HDM challenge, taken with the previous work showing a role for REV-ERB $\alpha$ in lung inflammation, prompted us to investigate HDM responses in Rev-erb $\alpha^{-/-}$ mice. There is an increase in AHR to $75 \mathrm{mg} \cdot \mathrm{mL}^{-1}$ of methacholine after HDM challenge in Rev-erbo ${ }^{-/-}$ mice, as compared to controls ( $\mathrm{p}<0.03$ at ZT23 and $\mathrm{p}=0.09$ at ZT11), but no time of challenge effect (in contrast to WT mice) (figure $3 \mathrm{c}$ and supplementary figure S2a). There was no difference in the slope of the methacholine dose-response curves between Rev-erb ${ }^{-/-}$mice challenged with HDM at either ZT11 or ZT23, in contrast to WT mice. We also noted higher baseline AHR at ZT23 compared to ZT11 in PBS-treated Rev-erb $\alpha^{-1-}$ mice (figure 3c) and, although this was not significant, this trend was in anti-phase to the effect seen in WT mice (figure 1).

Furthermore, there was an increase in maximal effect of methacholine in $R e v-e r b \alpha^{-/-}$mice compared to WT mice for both PBS-challenged mice (supplementary figure S2b) and HDM-challenged mice (figure $3 \mathrm{~d})$. This suggests that loss of REV-ERB $\alpha$ causes exaggerated and clock-time independent AHR in response to methacholine challenge.

\section{Airway and lung inflammation reveal no time of challenge differences in Rev-erb $\alpha^{-/-}$mice}

There was a significant increase in the total number of cells in BAL and in the percentage of eosinophils following HDM challenge in Rev-erb $\alpha^{-/-}$mice, but with no time of challenge effect in either case, as previously seen in WT mice (figures $3 \mathrm{e}$ and $3 \mathrm{f}$ ). There was a significant increase in total cells in the lung digest following HDM challenge in Rev-erbo ${ }^{-1-}$ mice at ZT23, as compared to control mice, but no time of challenge difference (figure 4a). Lung eosinophils also increased after HDM challenge (only reaching significance at ZT11) and there was no time of challenge difference (figure $4 \mathrm{~b}$ ).

Histological analysis showed increased $\mathrm{H}$ and $\mathrm{E}$ staining around the bronchioles and blood vessels, and within the interstitial spaces (as well as increased PAS staining), at both challenge times after HDM challenge, with no time of day effect in the Rev-erb $\alpha^{-/-}$mice (figures $4 \mathrm{c}$ and $4 \mathrm{~d}$ ). Following HDM challenge in Rev-erb $\alpha^{-/-}$mice, HDM-specific IgE was increased but no time of day difference was seen (supplementary figure S2c).

\section{Genotype comparison of wild-type versus Rev-erb $\alpha^{-1-}$ mice}

Individual cell counts in BAL, measured as a percentage of the total cell count, revealed no significant genotype differences (supplementary figure S3a). In addition, cytokine and chemokine analysis revealed no time of challenge differences (data not shown) and only CXCL13 showed a genotype difference (table 2).

\section{REV-ERB $\alpha$ action is through airway smooth muscle muscarinic receptor regulation}

Since we did not find a convincing correlation between inflammatory parameters and AHR in our models, we next investigated bronchiolar smooth muscle function. Using precision cut lung sections in organotypic culture we quantified airway contraction in response to methacholine. 
a)
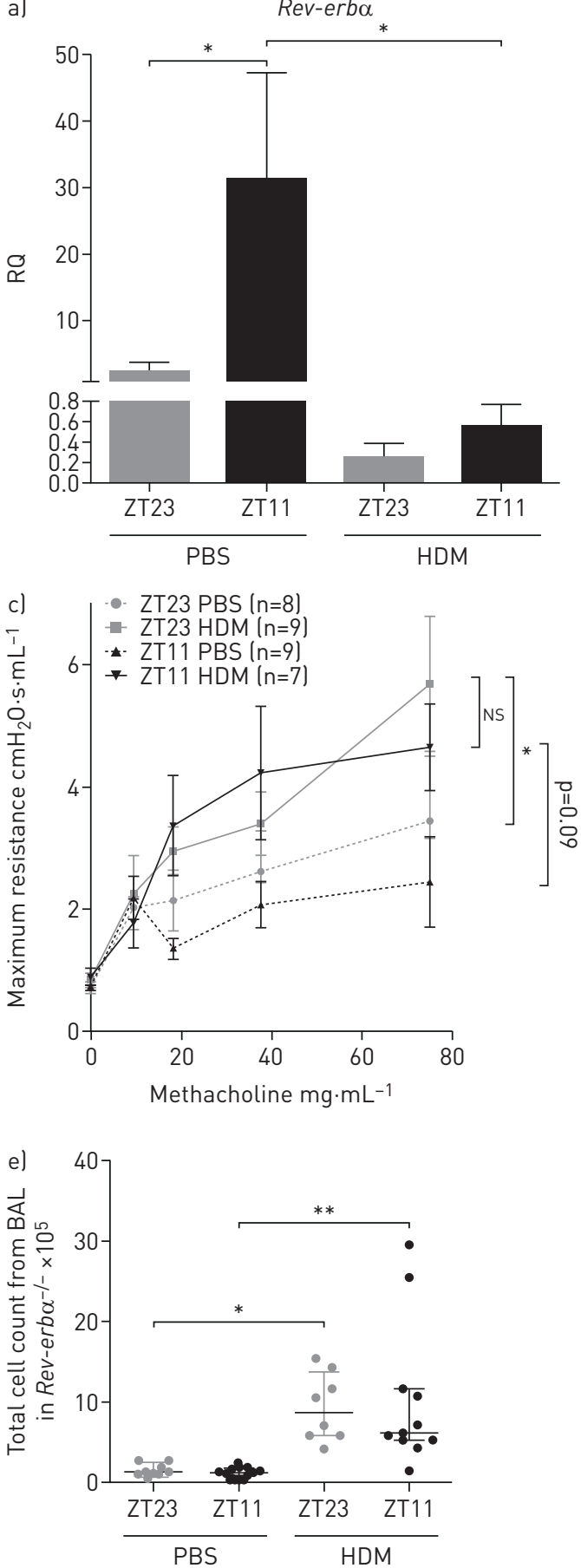

b) Bmal1
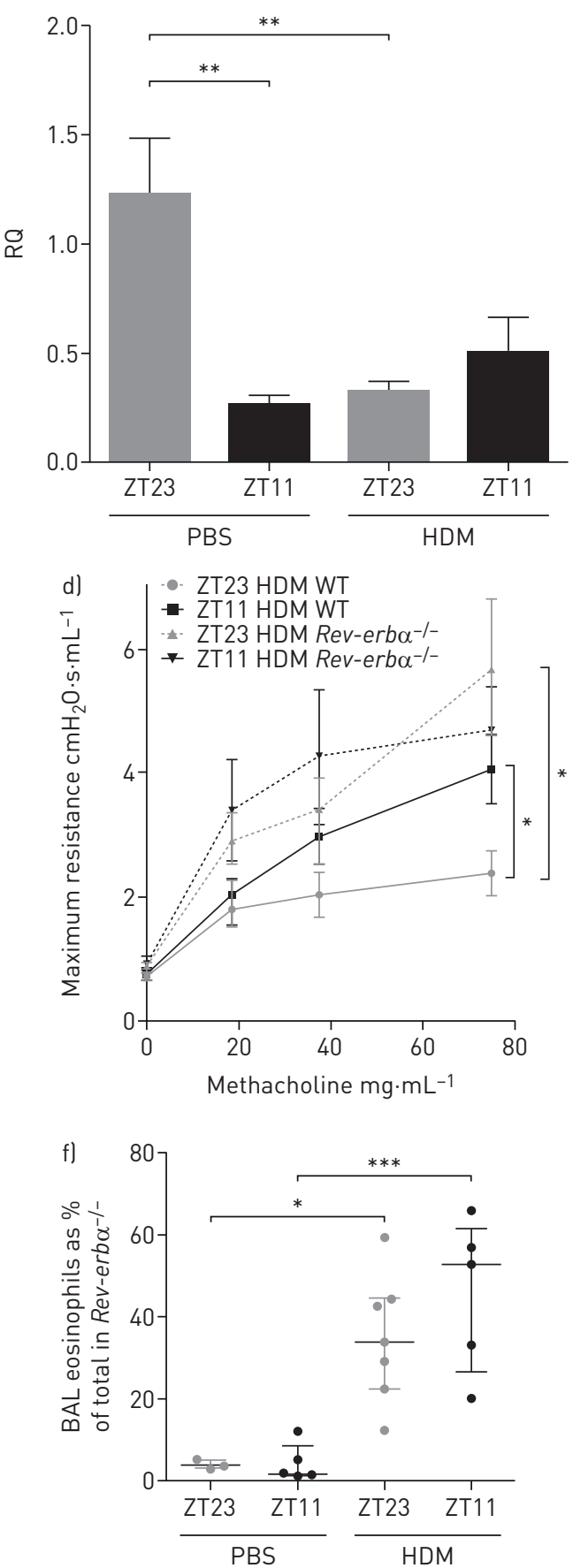

FIGURE 3 REV-ERB $\alpha$ is a negative repressor of airway hyper-responsiveness (AHR). Panels are as follows: a) expression of Rev-erbo in wild-type (WT) murine lung tissue, relative to the expression of Gapdh. A time of day difference was observed in the expression of Rev-erbo in phosphate-buffered saline (PBS)-challenged mice, with expression at ZT11 being significantly greater than expression at ZT23 ( $<<0.05)$. This difference was lost on house dust mite (HDM)-challenge and there was a reduction in expression of Rev-erb $\alpha$ at both challenge times $(p<0.05$ for ZT11) (data: mean \pm SEM; one-way ANOVA, followed by Tukey's multiple comparison test, $n=5-7$ per treatment group, in duplicate); b) expression of Bmal1 in WT murine lung tissue, relative to the expression of Gapdh. There was a time of day difference in the expression of Bmal1 in PBS-challenged mice, with expression at ZT23 being significantly greater than expression at ZT11 ( $p<0.01)$, in anti-phase to Rev-erbo expression. This time of day difference was lost after HDM challenge and there was a reduction in expression of Bmal1 at ZT23 ( $\mathrm{p}<0.01$ ) (data: mean \pm SEM; one-way ANOVA, followed by Tukey's multiple comparison test, $n=7-11$ per treatment group, in duplicate); c) AHR to increasing dosage of methacholine was measured as maximum airway resistance in Rev-erbo ${ }^{-/-}$mice using FlexiVent. There was no difference in the slopes of the methacholine dose-response curves between Rev-erbo-/- mice challenged with HDM at either ZT11 or ZT23 (by mixed linear modelling). Furthermore, there was no significant difference in the maximal AHR measured after 
$75 \mathrm{mg} \cdot \mathrm{mL}^{-1}$ of methacholine in Rev-erbo ${ }^{-/-}$mice after HDM challenge at ZT11 and at ZT23 (by Mann-Whitney U-test). However, mice challenged with HDM exhibited increased airway resistance after $75 \mathrm{mg} \cdot \mathrm{mL}^{-1}$ of methacholine when challenged at ZT23 $(p=0.03)$ and at ZT11 ( $p=0.09)$ compared to control (PBS-challenged) mice (by Mann-Whitney U-test). In Rev-erbo ${ }^{-1-}$ mice, baseline airway resistance is higher in control (PBS-treated) mice challenged at ZT23 compared to those challenged at ZT11, in anti-phase to WT mice (figure 1) (data: mean \pm SEM); d) AHR was significantly increased in Rev-erbo ${ }^{-/-}$mice after challenge with HDM compared to WT controls. After HDM challenge at ZT23 there was a significant increase $(p<0.05)$ in the maximal

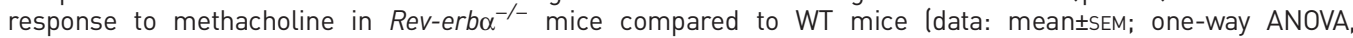
followed by Tukey's multiple comparison test, $n=7-9$ per treatment group); el total cells recovered from bronchoalveolar lavage (BAL) of Rev-erbo ${ }^{-/-}$mice significantly increased after HDM challenge at both ZT11 and ZT23 compared to PBS-challenged (control) mice ( $p<0.05$ at ZT23 and $p<0.01$ at ZT11). There was no time of challenge difference in total cell count for BAL in either the PBS-challenged or the HDM-challenged groups (data: median \pm IQR; one-way ANOVA, followed by Tukey's multiple comparison test, $n=8-12$ per treatment group); f) BAL eosinophils (measured as a percentage of the total) significantly increased after HDM challenge at both ZT11 and ZT23 in Rev-erbo ${ }^{-1-}$ mice compared to PBS-challenged (control) mice ( $<<0.05$ at ZT23 and $p<0.001$ at ZT11). There was no time of challenge difference in percentage of eosinophils in BAL for either the PBS-challenged or the HDM-challenged groups (data: median \pm QR; one-way ANOVA, followed by Tukey's multiple comparison test, $n=8-12$ per treatment group). RQ: relative quantification; SEM: standard error of the mean; IQR: interquartile range. ${ }^{*}: p<0.05 ;{ }^{* *}: p<0.01 ;{ }^{* * *}: p<0.001$.

We found a significant increase in the maximal effect to methacholine at ZT11 compared to ZT23 $(\mathrm{p}=0.03)$ and a reduction in the $\mathrm{EC}_{50}$ value for methacholine in HDM-challenged lung slices at ZT11 $(3.2 \mu \mathrm{M})$ compared to ZT23 $(6.2 \mu \mathrm{M})$ (figures $5 \mathrm{a}$ and $5 \mathrm{~b}$ ). We repeated these experiments in lung slices from HDM-challenged Rev-erb $\alpha^{-/-}$mice and found no time of day differences to methacholine challenge, as well as similar $\mathrm{EC}_{50}$ values (ZT11: $\mathrm{EC}_{50} 9.3 \mu \mathrm{M}$ and $\mathrm{ZT} 23: \mathrm{EC}_{50} 8.5 \mu \mathrm{M}$ ) (figure $5 \mathrm{c}$ ). There were no changes by time of day in PBS-treated lung slices.

We then investigated muscarinic receptor expression in the lungs. After saline challenge, we found Chrm 1 was more highly expressed at ZT11 rather than at ZT23, perhaps accounting for the physiological differences in AHR at baseline by time of day in WT mice (figure 5d). We also found Chrm 3 expression was higher after HDM challenge at ZT11, but not at ZT23, potentially explaining the time of challenge difference in AHR. These time of day effects were lost in Rev-erb $\alpha^{-/-}$mice (figure 5f). Chrm 2 expression showed no time of day or genotype differences after PBS or HDM challenge (figure 5e).

We also measured the expression of the muscle contractile apparatus genes smooth muscle actin (Acta), myosin light chain kinase $(m y l k 1)$ and smooth muscle myosin $(s m-m h c)$. None of these demonstrated a time of day response (supplementary figures S4a-S4c). Similarly, the beta adrenoceptors Adrb1 and Adrb2, although reduced in response to HDM challenge, importantly also showed no time of day effects (supplementary figures S4d and S4e).

\section{Discussion}

We show that AHR is determined by time of day, an effect regulated through REV-ERB $\alpha$. Allergen challenge at ZT11 (just before lights off/beginning of the active phase in mice and equivalent to early morning in humans) significantly increases the magnitude of AHR compared to allergen challenge at ZT23 (just before lights on/beginning of the rest phase in mice and equivalent to late afternoon/early evening in humans). This effect is abolished in Rev-erb $\alpha^{-/-}$mice, suggesting that AHR is regulated, or gated, by REV-ERB $\alpha$. Despite the marked changes in AHR, only modest changes in inflammatory mediators and cells were seen in the lungs, suggesting dissociation between inflammatory response and airway constriction. Even ex-vivo the airways retain a time of day signature in response to methacholine, an effect which was lost in Rev-erb $\alpha^{-/-}$mice and which prompted our analysis of the muscarinic receptor types. This revealed both time of day and also REV-ERB $\alpha$ dependent changes in expression, especially of the M3 receptor in whole lung.

Nocturnal exacerbations of asthma, hospital admissions and deaths remain an unmet medical need. The immune system lies under strong circadian control $[23,24]$ and lung inflammatory responses are strongly regulated by the circadian clock, specifically by $\operatorname{REV-ERB} \alpha[16,18]$. Since human asthma symptoms peak in the early morning, at around 6am, we focussed on this time point (ZT11) and its anti-phasic time point ZT23 in our mouse studies. These time points have also been shown to be important for lung innate immune response and in food allergy [31,32], as well as in our own work on human asthma [1]. Using direct FlexiVent measurement of AHR and a physiologically relevant allergen, HDM, we found higher AHR at ZT11. In nocturnal mice, this time-point is equivalent to the transition from the rest phase to activity and is biologically comparable to early morning in humans. 

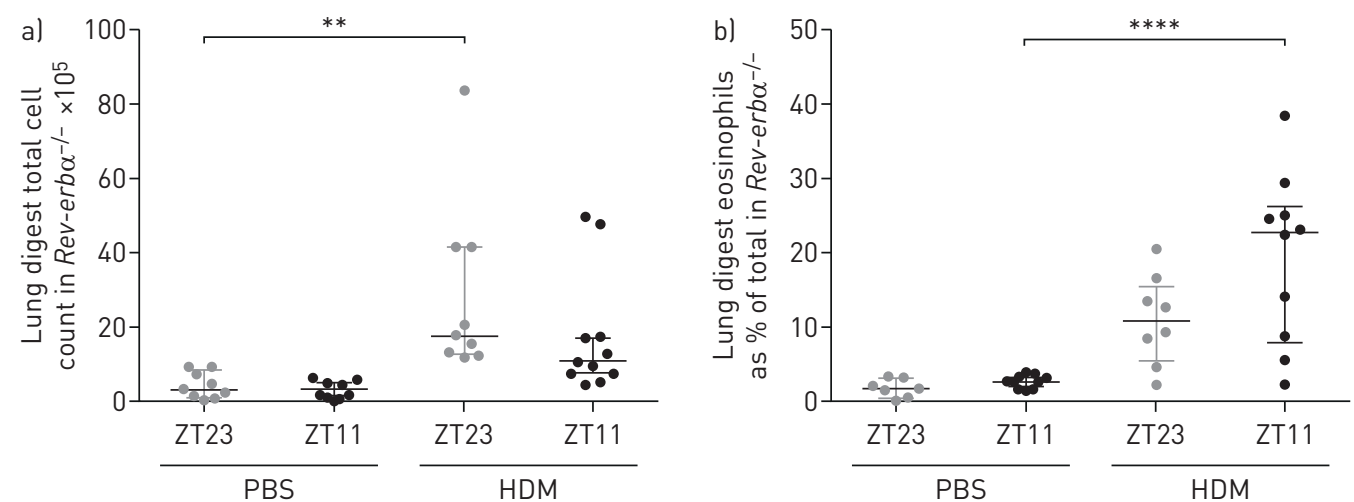

c)

$\mathrm{H}$ and $\mathrm{E}$

i)

ZT23

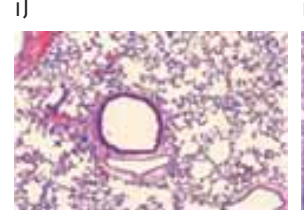

iii)

ZT11

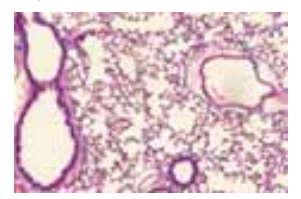

PBS

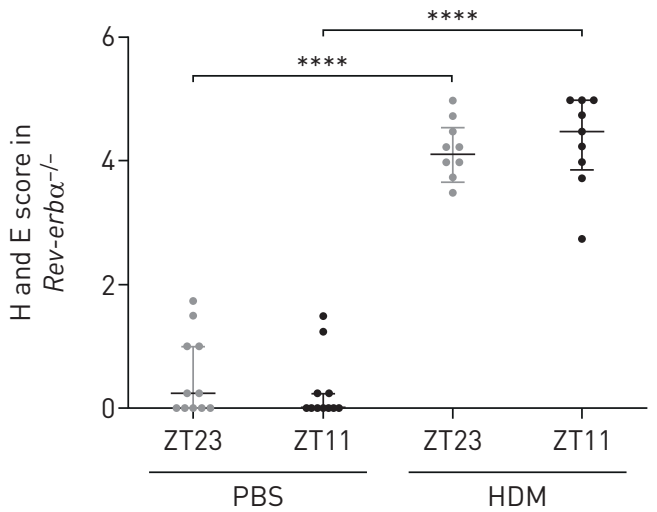

ii)

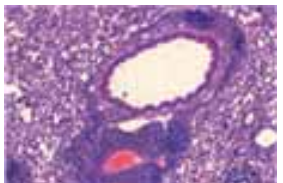

iv)

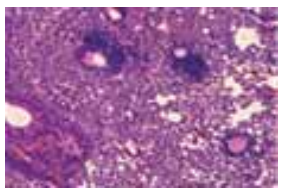

HDM d)

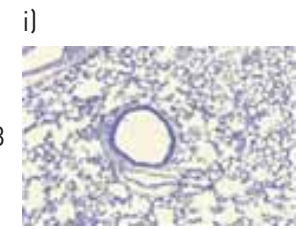

iii)

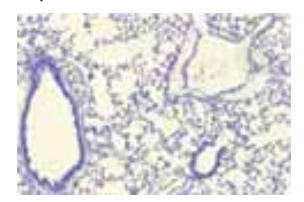

PBS

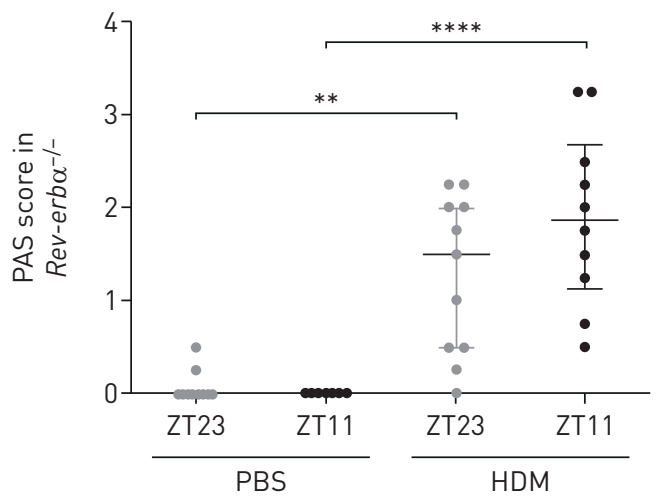

FIGURE 4 Lung inflammation in Rev-erbo ${ }^{-/-}$mice after house dust mite (HDM) challenge show no time of challenge difference. Panels are as follows: al total cell count from lung digests increased after HDM challenge, compared to phosphate-buffered saline (PBS)-challenged controls, although this only reached significance at ZT23 $(p<0.01)$. There was no time of challenge difference (data: median \pm IQR; one-way ANOVA, followed by Tukey's multiple comparison test, $n=8-11$ per treatment group); b) eosinophils in lung digests increased after HDM-challenge, only reaching significance at ZT11 $(p<0.0001)$. There was no time of challenge difference (data: median \pm IQR; one-way ANOVA, followed by Tukey's multiple comparison test, $n=8-11$ per treatment group); c) HDM-challenge at ZT11 and ZT23 caused predominantly eosinophilic inflammation around the bronchioles and blood vessels (by haemoatoxylin $(\mathrm{H})$ and eosin (E) staining) compared to PBS-challenge (subpanels i-iv and associated scatter plot for $\mathrm{H}$ and $\mathrm{E}$ score) ( $p<0.0001$ at ZT23 and at ZT11). There was no significant time of challenge effect in PBS-challenged groups or HDM-challenged groups (data: median \pm IQR one-way ANOVA, followed by Tukey's multiple comparison test, $n=9-11$ per treatment group); d) periodic acidSchiff (PAS) staining shows the presence of increased mucus on the bronchial epithelium in the lungs of Rev$e^{e r b \alpha^{-1-}}$ mice treated with HDM at both ZT11 and ZT23. There was no PAS staining seen in PBS-treated mice (subpanels i-iv and scatter plot for PAS score) ( $p<0.01$ at ZT23 and $p<0.0001$ at ZT11). There was no time of challenge difference after either PBS-challenge or HDM-challenge (data: median \pm IQR; one-way ANOVA followed by Tukey's multiple comparison test, $n=9-11$ per treatment group). IQR: interquartile range. ${ }^{* *}: p<0.01$; $* * * *$ : $p<0.0001$. 
TABLE 2 Cytokine/chemokine detection in bronchoalveolar lavage fluid (BALF) at ZT11 and ZT23 after house dust mite (HDM) challenge in wild-type (WT) and Rev-erbo ${ }^{-1-}$ mice

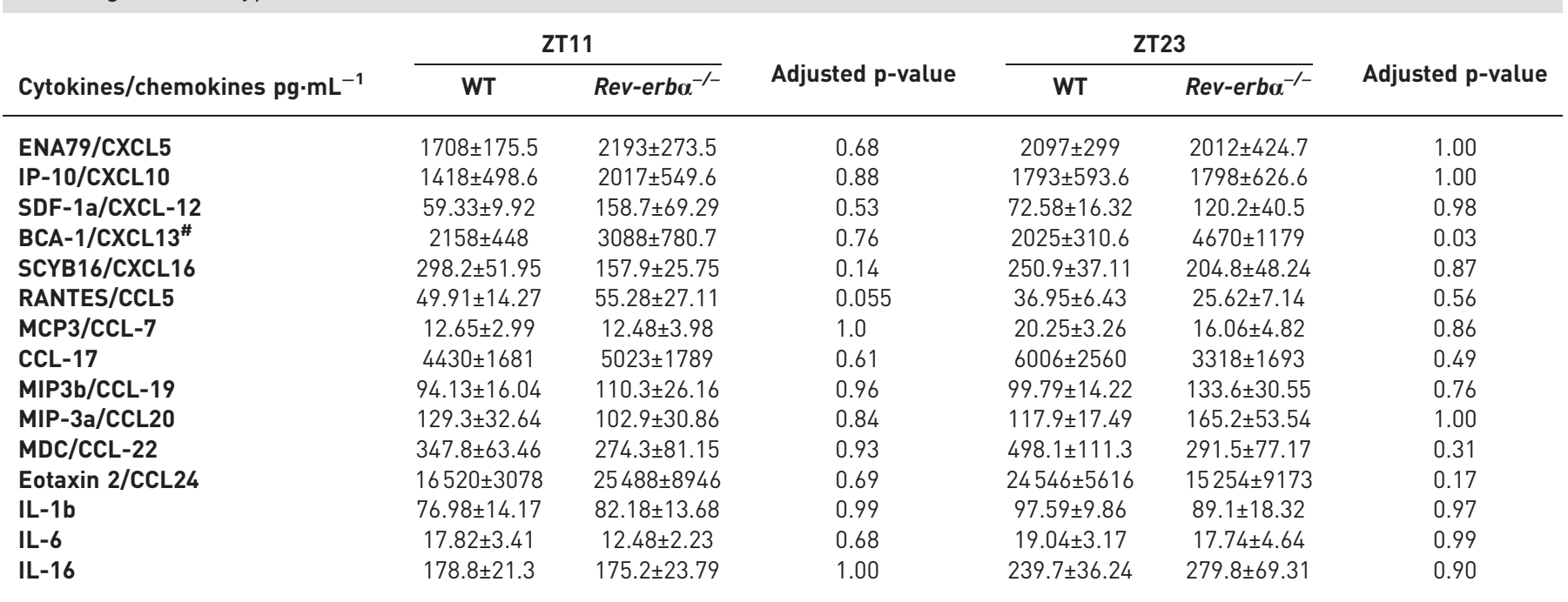

Data are presented as mean \pm SEM, unless otherwise stated. Cytokines/chemokines that increased significantly in BALF after intra-nasal HDM challenge are shown. $\mathrm{p}$-values are given as for table 1 (ANOVA, followed by the Tukey multiple comparison adjustment ( $\mathrm{n}=8-12$ per treatment groupl). \#: BCA-1/CXCL13 showed a genotype effect and was increased in Rev-erbo ${ }^{-1-}$ mice at ZT23 compared to WT mice (p<0.03).

The allergic inflammatory process recruits many specialised cells to the lung, resulting in a changed immune environment. We characterised the immune cell repertoire, both in BAL and in lung digests, and also measured inflammatory and immune mediators. Overall, the effects of time of day were dissociated from the consistent and marked changes in AHR, suggesting possible non-immune cell involvement. We acknowledge that there could have been time of day differences at other time points. Our sampling was undertaken at $24 \mathrm{~h}$ after the final allergen challenge, when AHR was predicted to be greatest [20].

The orphan nuclear receptor REV-ERB $\alpha$ has recently emerged as a major regulator of the lung immune response, mediating time of day changes to acute inflammatory challenges $[16,18]$. Moreover, REV-ERB $\alpha$ plays important roles in non-immune cells, regulating energy metabolism and in muscle function [33, 34]. For these reasons we repeated the HDM challenges in Rev-erb $\alpha^{-/-}$mice and showed that the time of day AHR effect was abolished. Interestingly, we also found that HDM challenge in WT mice had a major inhibitory effect on Rev-erb $\alpha$ expression, identifying inflammation acting through both transcriptional and post-translational mechanisms to repress Rev-erb $\alpha$ expression [18]. Again, we saw no differences in immune cells infiltrating into the lungs between WT and Rev-erbo ${ }^{-1-}$ mice, despite the loss of temporal control of AHR. This again suggests a non-immune cell and non-inflammatory effector mechanism.

To examine airway response directly, we removed the lungs of HDM-sensitised animals, prepared precision cut lung slices for organotypic culture and measured airway responses to methacholine. Here, we saw an increase in the maximal effect to methacholine at ZT11, indicating greater methacholine sensitivity. Furthermore, when we repeated these experiments in Rev-erb $\alpha^{-/-}$mice, the time of day difference was abolished. This correlates with the in-vivo measurements and indicates a lung-intrinsic mechanism of action. Methacholine acts on muscarinic receptors, with little effect on nicotinic receptors [35]. Therefore, we examined the expression of muscarinic receptors and identified major changes in both Type M1 and Type M3 muscarinic receptors. Importantly, we found no changes in the expression of genes involved in the contractile apparatus of airway muscle, or in adrenoceptors, suggesting that the changes in muscarinic receptors in the lung by time of day were specific. The increase in M1 receptor expression at ZT11 in the PBS-treated group suggests that this receptor is important for conferring time of day constrictor tone to the airway under basal conditions. Furthermore, Chrml contains transcription factor binding sites for the clock proteins BMAL:CLOCK and ROR $\beta$ [36]; suggesting that muscarinic receptor one (Chrm 1) is under direct clock control. In contrast muscarinic receptor three (Chrm 3$)$ only acquires a time of day effect after HDM-inflammation, with peak expression at ZT11. Strikingly, this time of day change in Chrm 3 expression is completely lost in the Rev-erba ${ }^{-/-}$mouse, providing an attractive explanation for the loss of temporal gating in AHR that we observed. However, according to the Circadian Database [37] of rhythmic gene expression, the expression of Chrm 3 oscillates in healthy mouse lung with maximal expression at $6 \mathrm{pm}$ (ZT11) and nadir of expression at 6 am (ZT23). In our study, we identified similar time of day 
a)

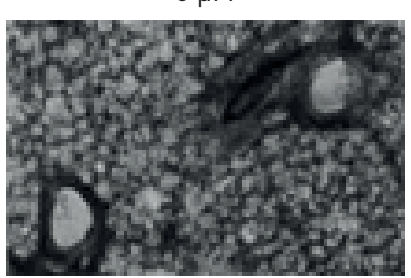

ZT23

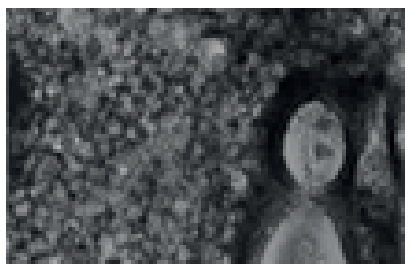

$2 \mu \mathrm{M}$
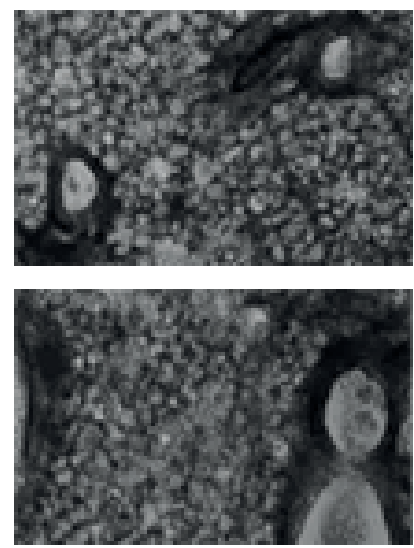

$10 \mu \mathrm{M}$
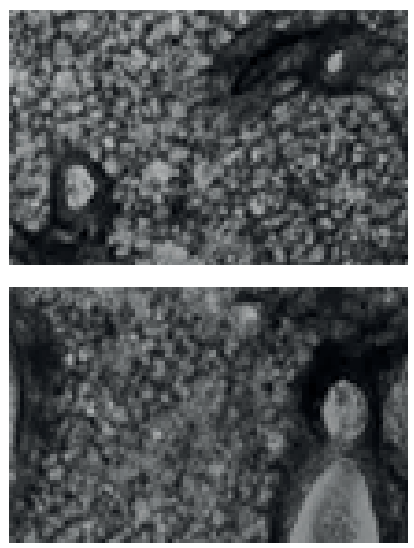

b)

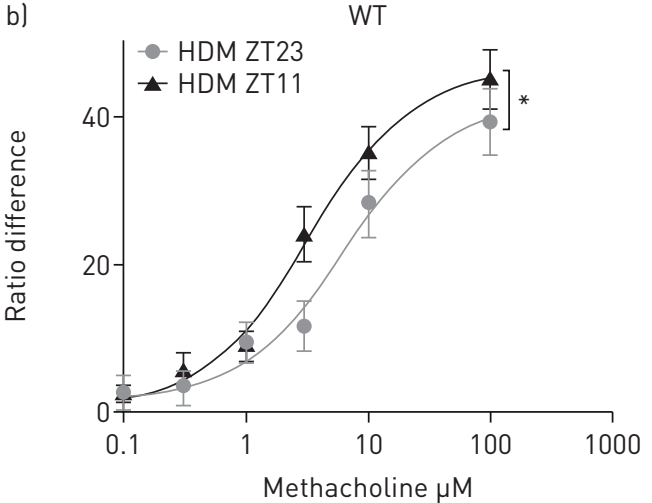

c)

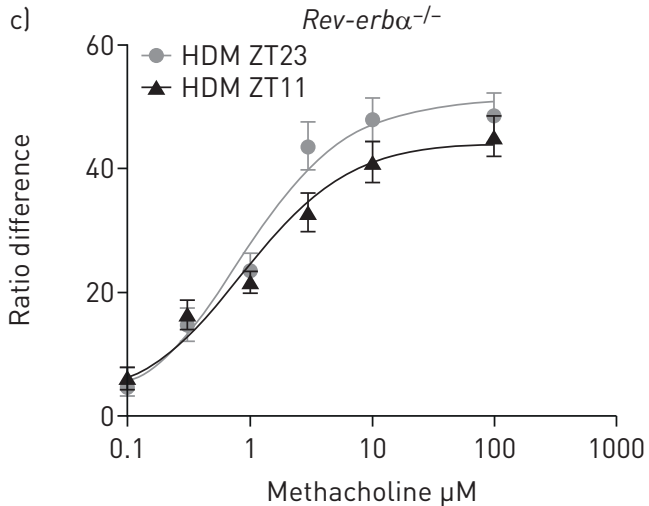

d)

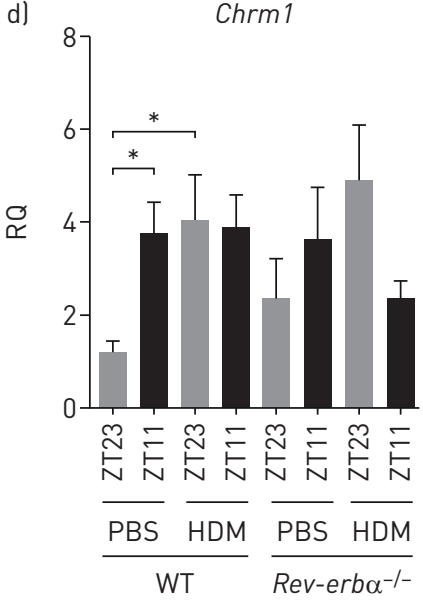

e)

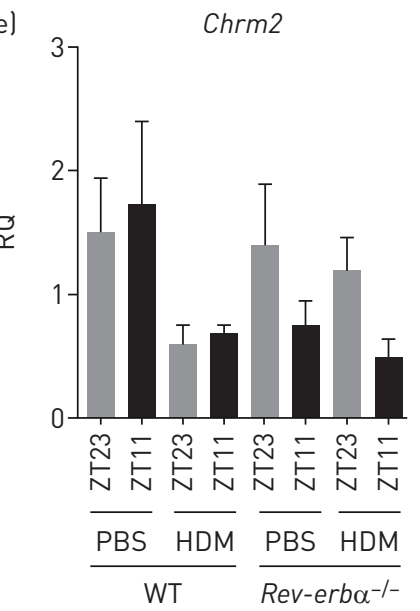

f)

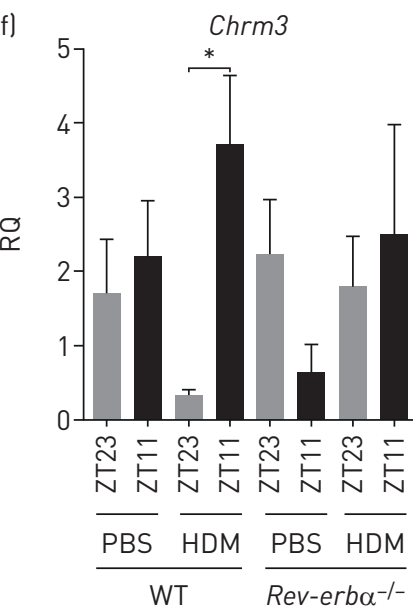

FIGURE 5 Time of house dust mite (HDM) challenge determines the magnitude of contraction of the airways caused by methacholine in the lung slice model. Muscarinic receptor expression is regulated by time of day, HDM challenge and REV-ERB $\alpha$. Panels are as follows: a) representative images of precision cut lung slices showing contraction of airways due to increasing concentrations of methacholine in mice challenged with HDM at ZT11 or ZT23; b) concentration-response curves for increasing concentration of methacholine in wild-type (WT) mice. There is a significant increase in the maximal effect of methacholine in mice challenged with HDM at ZT11 compared to ZT23 ( $p=0.03$ ). The $\mathrm{EC}_{50}$ value was $3.2 \mu \mathrm{M}$ at ZT11 and $6.2 \mu \mathrm{M}$ at ZT23; c) concentration-response curves for increasing concentration of methacholine in Rev-erba ${ }^{-/-}$mice challenged with HDM at ZT11 and ZT23. There was no difference in the effect of methacholine by time of day. The $\mathrm{EC}_{50}$ value was $9.3 \mu \mathrm{M}$ for $\mathrm{ZT} 11$ and $8.5 \mu \mathrm{M}$ for ZT23. Methacholine dose-response curves were fitted to a three-parameter sigmodal dose-response curve. An extra sum-of-squares F-test was used to test whether one curve could adequately fit the data for ZT11 and ZT23; d) quantitative PCR for muscarinic receptor one (Chrm 1). Chrm 1 expression is significantly increased in phosphate-buffered saline (PBS)-challenged mice at ZT11 compared to ZT23 ( $p<0.05)$. This time of day difference is not apparent after HDM challenge. There is also a significant increase in expression of $\mathrm{Chrm} 1$ after HDM challenge at ZT23 compared to PBS-challenged (control) mice $(p<0.05)$. There was no time of challenge difference seen in Rev-erbo ${ }^{-/-}$mice $(n=5-9$ per treatment group, in duplicate); e) quantitative PCR for muscarinic receptor two (Chrm 2). Chrm 2 expression 
showed no time of challenge differences in WT mice or in Rev-erbo ${ }^{-/-}$mice ( $n=7-10$ per treatment group, in duplicate); f) quantitative PCR for muscarinic receptor three (Chrm 3). Chrm 3 expression was significantly increased in WT mice after HDM challenge at ZT11, compared to ZT23 ( $p<0.05)$, and there was no time of day difference in Rev-erbo ${ }^{-1-}$ mice (data: mean \pm SEM; one-way ANOVA, followed by Tukey's multiple comparison test, $n=5-9$ per treatment group, in duplicate). All quantitative PCR data is compared to expression of the housekeeping gene Gapdh in WT, PBS-challenged mice at ZT23. SEM: standard error of the mean; RQ: relative quantification. * $\mathrm{p}<0.05$.

differences in Chrm 3 expression; however, in our case, these differences were only apparent following stimulation with HDM and were not observed under baseline conditions. One potential explanation may be that our assay was insufficiently sensitive for the detection of low level changes in gene transcription under unstimulated conditions. Bioinformatic analysis revealed no evidence of clock transcription factor binding sites in Chrm 3 [36] and we therefore postulate that Chrm 3 transcription may be under indirect clock control.

We acknowledge that the M3 receptor is not only expressed by airway smooth muscle cells but by multiple other cell types [38], including endothelial cells and inflammatory cells. However, given the immediate and directly visualised contraction of the airway to methacholine during the lung slice experiments, the likely mechanism of action of methacholine is through the muscarinic receptors present in the airway smooth muscle. Although we have focussed on time of day changes in muscarinic receptors, it should be noted that the parasympathetic nervous system as a whole displays marked circadian rhythmicity [39]. It is therefore likely that in vivo the diurnal variation in AHR would be affected by both neural and humoral circadian rhythms, as well as by rhythmic changes in receptor expression.

To our knowledge this is the first time that the molecular clock has been shown to be important in gating AHR. Furthermore, the discovery that muscarinic receptors might play a role is important for the treatment of asthma [40]. The cholinergic system is functionally linked to the circadian system [39]. Tiotropium bromide, a long-lasting M3 muscarinic-receptor antagonist, is licensed for asthma [41]. In the future, a short-acting drug antagonising both M1 and M3 might prevent AHR in asthma and its administration at the peak of receptor expression could significantly increase its efficacy, leading to novel chronotherapeutic approaches.

Author contributions: H.J. Durrington conceived of the study, secured the funding, ran the study, analysed the results and prepared the manuscript. K. Krakowiak performed Bioplex, PCR, histology, cell counts and lung slice experiments. P. Meijer performed lung slice experiments. N. Begley and L. Goosey performed FlexiVent measurements and collected samples. L.G. Gregory and C.M. Lloyd advised on the house dust mite model and FlexiVent measurements, and helped to prepare the manuscript. R. Maidstone ran statistical analysis and advised on the statistics used and prepared the manuscript. A.S.I. Loudon, J.E. Gibbs and J.F. Blaikley prepared the manuscript. J.F. Blaikley also advised on lung slice experiments. D.W. Ray conceived the study, analysed the results and prepared the manuscript.

Conflict of interest: None declared.

Support statement: H.J. Durrington is supported by an Asthma UK Senior Clinical Academic Development Award (AUK-SCAD-2013-229), the JP Moulton Charitable Foundation, a North West Lung Centre charity project grant ( $\mathrm{R}$ 121399) and the University of Manchester's Dean's Prize for Clinicians. K. Krakowiak is supported by the JP Moulton Charitable Foundation. P. Meijer is supported by Medical Research Council Doctoral Training Partnership funding (AA07 P117413). R. Maidstone is funded by a Wellcome Trust grant (107849/Z/15/Z) and a Medical Research Council grant (MR/P023576/1). J.E. Gibbs is a Career Development Fellow versus Arthritis (20629) and holds a Medical Research Council grant (MR/S002715/1). C.M. Lloyd is a Wellcome Senior Fellow in Basic Biomedical Sciences (107059/Z/15/Z). A.S.I. Loudon is a Wellcome Investigator (Wellcome Trust 107849/Z/15/Z). D.W. Ray is a Wellcome Investigator (Wellcome Trust 107849/Z/15/Z) and holds a Medical Research Council grant (MR/P023576/1). J.F. Blaikley is funded by a Medical Research Council grant (MR/L006499/1). Funding information for this article has been deposited with the Crossref Funder Registry.

\section{References}

1 Durrington HJ, Gioan-Tavernier GO, Maidstone RJ, et al. Time of day affects eosinophil biomarkers in asthma: implications for diagnosis and treatment. Am J Respir Crit Care Med 2018; 198: 1578-1581.

2 Durrington HJ, Farrow SN, Loudon AS, et al. The circadian clock and asthma. Thorax 2014; 69: 90-92. Turner-Warwick M. Nocturnal asthma: a study in general practice. J R Coll Gen Pract 1989; 39: 239-243. Sutherland ER. Nocturnal asthma. J Allergy Clin Immunol 2005; 116: 1179-1186.

Cochrane GM, Clark JH. A survey of asthma mortality in patients between ages 35 and 64 in the Greater London hospitals in 1971. Thorax 1975; 30: 300-305.

6 British Thoracic Society (BTS), Scottish Intercollegiate Guidelines Network (SIGN). British guideline on the management of asthma: a national clinical guideline (SIGN 153). London/Edinburgh, BTS/SIGN, 2016. www. brit-thoracic.org.uk/quality-improvement/guidelines/asthma/ Date last updated: September, 2016.

7 Global Initiative for Asthma (GINA). Global strategy for asthma management and prevention. GINA, 2018. https://ginasthma.org/wp-content/uploads/2019/01/2018-GINA.pdf Date last updated: 2018. 
8 De Vries K, Goei JT, Booy-Noord H, et al. Changes during $24 \mathrm{~h}$ in the lung function and histamine hyperreactivity of the bronchial tree in asthmatic and bronchitic patients. Int Arch Allergy Appl Immunol 1962; 20: 93-101.

9 Reinberg A, Gervais P, Morin M, et al. Circadian rhythms in the threshold of bronchial response to acetylcholine in healthy and asthmatic subjects. In: Scheving L, Halberg F, Pauly J, eds. Int. Soc. Chronolbiol. Meeting, Little Rock, November 1971. Tokyo, Igaku Shoin Ltd, 1974; pp. 174-177.

10 Bonnet R, Jorres R, Heitman U, et al. Circadian rhythm in airway responsiveness and airway tone in patients with mild asthma. J Appl Physiol 1991; 71: 1598-1605.

11 Kondo S, Abe K. Priority of peak circadian variation of bronchial responsiveness to the trough of circadian variation of bronchial caliber in asthmatic children. Chest 1991; 100: 640-643.

12 Van Aalderen WMC, Postma DS, Koeter GH, et al. Circadian change in bronchial responsiveness and airflow obstruction in asthmatic children. Thorax 1989; 44: 803-807.

13 Gervais P, Reinberg PA, Gervais C, et al. Twenty-four-hour rhythm in the bronchial hyperreactivity to house dust in asthmatics. J Allergy Clin Immunol 1977; 59: 207-213.

14 Mohawk JA, Green CB, Takahashi JS. Central and peripheral circadian clocks in mammals. Annu Rev Neurosci 2012; 35: 445-462.

15 Bellet MM, Deriu E, Liu JZ, et al. Circadian clock regulates the host response to Salmonella. Proc Natl Acad Sci USA 2013; 110: 9897-9902.

16 Gibbs JE, Blaikley J, Beesley S, et al. The nuclear receptor REV-ERB $\alpha$ mediates circadian regulation of innate immunity through selective regulation of inflammatory cytokines. Proc Natl Acad Sci USA 2012; 109: 582-587.

17 Narasimamurthy R, Hatori M, Nayak SK, et al. Circadian clock protein cryptochrome regulates the expression of proinflammatory cytokines. Proc Natl Acad Sci USA 2012; 109: 12662-12667.

18 Pariollaud M, Gibbs JE, Hopwood TW, et al. Circadian clock component REV-ERB $\alpha$ controls homeostatic regulation of pulmonary inflammation. J Clin Invest 2018; 128: 2281-2296.

19 Cates EC, Fattouh R, Johnson JR, et al. Modeling responses to respiratory house dust mite exposure. Contrib Microbiol 2007; 14: 42-67.

20 Gregory LG, Causton B, Murdoch JR, et al. Inhaled house dust mite induces pulmonary T helper 2 cytokine production. Clin Exp Allergy 2009; 39: 1597-1610.

21 Preitner N, Damiola F, Molina L-L, et al. The orphan nuclear receptor REV-ERB $\alpha$ controls circadian transcription within the positive limb of the mammalian circadian oscillator. Cell 2002; 110: 251-260.

22 Hartney JM, Robichaud A. Assessment of airway hyperresponsiveness in mouse models of allergic lung disease using detailed measurements of respiratory mechanics. In: Allen IC, ed. Mouse models of allergic disease: methods and protocols (Methods in molecular biology, Vol. 1032). Totowa, Humana Press, 2013; pp. 205-217.

23 Zhang Z, Hunter L, Wu G, et al. Genome-wide effect of pulmonary airway epithelial cell-specific Bmall deletion. FASEB J 2019; 33: 6226-6238.

24 Gibbs J, Ince L, Matthews L, et al. An epithelial circadian clock controls pulmonary inflammation and glucocorticoid action. Nat Med 2014; 20: 919-926.

25 Lloyd CM, Gonzalo JA, Nguyen T, et al. Resolution of bronchial hyperresponsiveness and pulmonary inflammation is associated with Il-3 and tissue leukocyte apoptosis. J Immunol 2001; 166: 2033-2040.

26 Townsend JM, Fallon GP, Matthews JD, et al. IL-9 deficient mice establish fundamental roles for IL-9 in pulmonary mastocytosis and goblet cell hyperplasia but not T cell development. Immunity 2000; 13: 573-583.

27 Haspel JA, Chettimada S, Shaik RS, et al. Circadian rhythm reprogramming during lung inflammation. Immunity 2014; 5: 4753.

28 Ehlers A, Xie W, Agapov E, et al. BMAL1 links the circadian clock to viral airway pathology and asthma phenotypes. Mucosal Immunol 2018; 11: 97-111.

29 Edgar RS, Stangherlin A, Nagy AD, et al. Cell autonomous regulation of herpes and influenza virus infection by the circadian clock. PNAS 2016; 113: 10085-10090.

30 Hwang JW, Sundar IK, Yao H, et al. Circadian clock function is disrupted by environmental tobacco/cigarette smoke, leading to lung inflammation and injury via a SIRT1-BMAL1 pathway. FASEB J 2014; 28: 176-194.

31 He W, Holtkamp S, Hergenhan SM, et al. Circadian expression of migratory factors establishes lineage-specific signatures that guide the homing of leukocyte subsets to tissues. Immunity 2018; 49: 1175-1190.

32 Tanabe K, Kitagawa E, Wada M, et al. Antigen exposure in the late light period induces symptoms of food allergy in an OVA-allergic mouse model. Sci Reports 2015; 5: 14424.

33 Cho $\mathrm{H}$, Zhao X, Hatori $\mathrm{M}$, et al. Regulation of circadian behaviour and metabolism by REV-ERB $\alpha$ and REV-ERBB. Nature 2012; 485: 123-127.

34 Mayeuf-Louchart A, Thorel Q, Delhaye S, et al. Rev-erb- $\alpha$ regulates atrophy-related genes to control skeletal muscle mass. Sci Rep 2017; 7: 14383.

35 Coates AL, Wanger J, Cockcroft DW, et al. ERS technical standard on bronchial challenge testing: general considerations and performance of methacholine challenge tests. Eur Respir J 2017; 49: 1601526.

36 Daily K, Patel VR, Rigor P, et al. MotifMap: integrative genome-wide maps of regulatory motif sites for model species. BMC Bioinformatics 2011; 12: 495.

37 CircaDB. Circadian expression profiles database. http://circadb.hogeneschlab.org/

38 Schaum N, Karkanias J, Neff NF, et al. Single-cell transcriptomics of 20 mouse organs creates a Tabula Muris. Nature 2018; 562: 367-372.

39 Hut RA, Van der Zee EA. The cholinergic system, circadian rhythmicity, and time memory. Behav Brain Res 2011; 221: 466-480.

40 Gosens R, Gross N. The mode of action of anticholinergics in asthma. Eur Respir J 2018; 52: 1701247.

41 Global Initiative for Asthma (GINA). Global strategy for asthma management and prevention (2016 update). GINA, 2016. https://ginasthma.org/wp-content/uploads/2016/04/wms-GINA-2016-main-report-final.pdf 